\title{
13-Year-Old Boy with a 3-Day History of Melena*
}

Katie Traylor, Laura Gonzalez-Krellwitz, and Helena Balon

William Beaumont Hospital, Royal Oak, Michigan

A

13-y-old boy presented to the emergency center with a 3-d history of melena. On admission the patient was anemic (hemoglobin $=9.3 \mathrm{~g} / \mathrm{dL}$, hematocrit $=26.2 \%$ ). The patient was injected with $334 \mathrm{MBq}(9 \mathrm{mCi})$ of ${ }^{99 \mathrm{~m} T c-p e r t e c h n e t a t e}$. Anterior, posterior, and lateral views of the abdomen were acquired at 15, 40, and $60 \mathrm{~min}$ after injection.

\section{QUESTION 1}

On examining all the images, what is the ordering physician evaluating? Please select the best answer.

A. Gastrointestinal bleeding.

B. Bleeding from diverticulitis.

C. Meckel diverticulum.

D. Appendicitis.

A
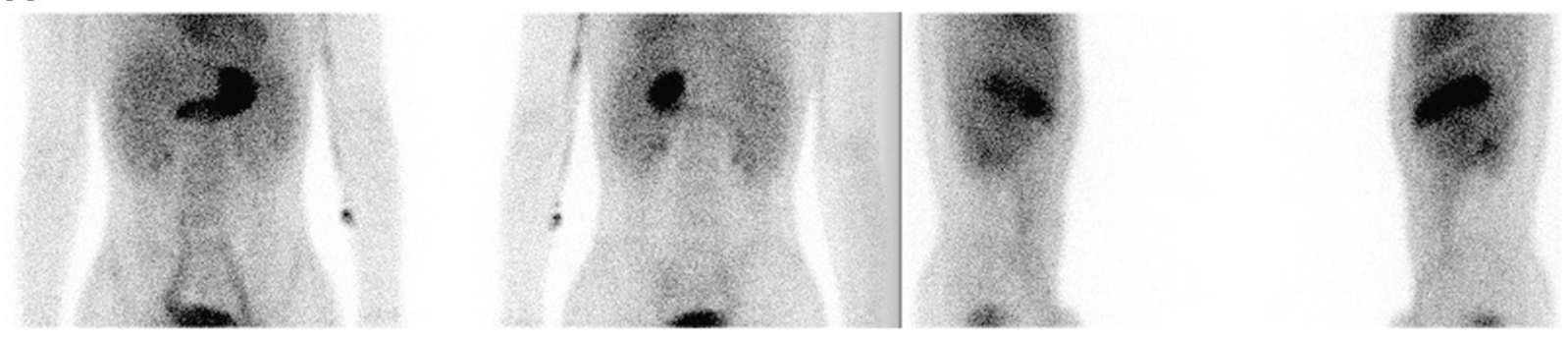

B
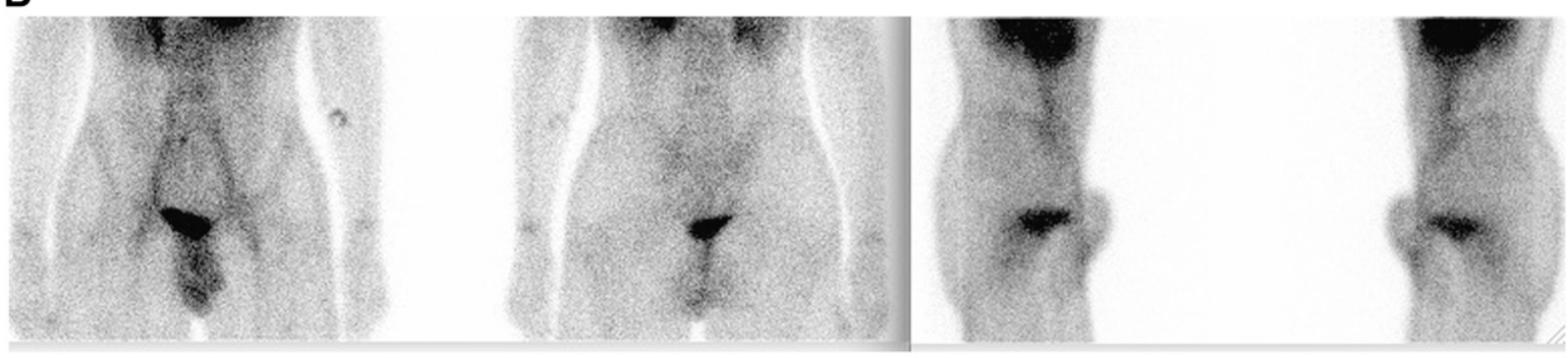

\section{C}
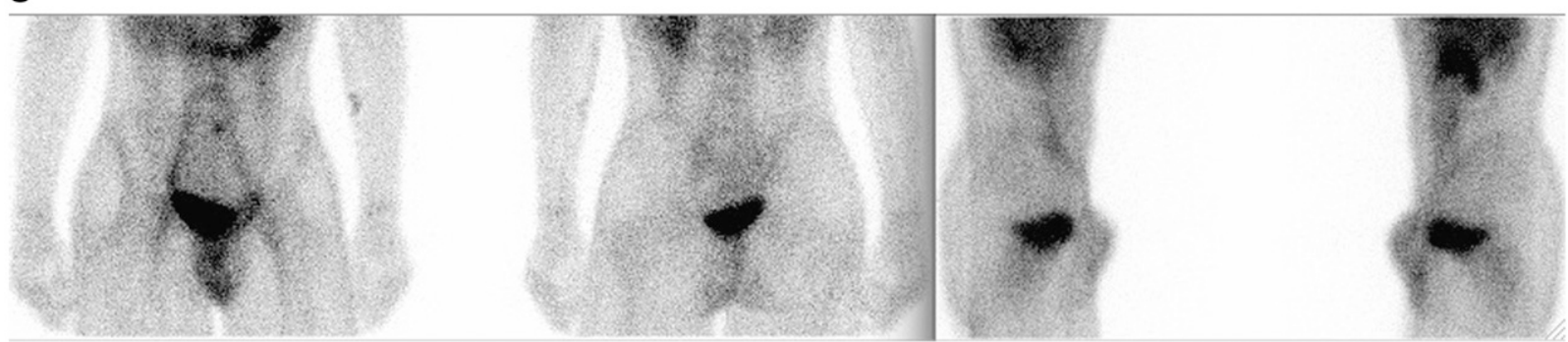

FIGURE 1. (A) Anterior, posterior, and lateral projections at $15 \mathrm{~min}$ after injection; (B) anterior, posterior, and lateral projections at 40 min after injection; and (C) anterior, posterior, and lateral projections at 60 min after injection.

Published online May 8, 2012.

DOI: 10.2967/jnmt.112.106310

COPYRIGHT @ 2012 by the Society of Nuclear Medicine, Inc. 


\section{QUESTION 2}

Which of the following would cause a false-negative finding on a Meckel scan?
A. Ulcerative colitis.
B. Intestinal obstruction.
C. Laxative abuse.
D. Irritable bowel in the right lower quadrant.

FIGURE 2. Anterior and posterior projections at $60 \mathrm{~min}$ after injection. Arrow illustrates focus of ectopic gastric mucosa in Meckel diverticulum.
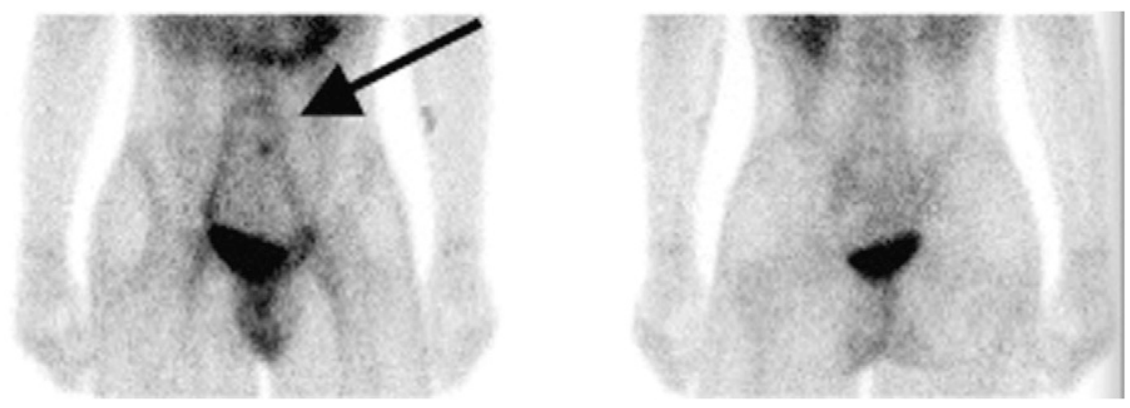

\section{QUESTION 3}

What pharmacologic interventions can be used to improve visualization of the Meckel diverticulum by decreasing bowel peristalsis?

A. $20 \mathrm{mg}$ of cimetidine per kilogram per day for $2 \mathrm{~d}$ before study.

B. $50 \mu \mathrm{g}$ of glucagon per kilogram administered intravenously 5-10 min before the study.

C. $6 \mu \mathrm{g} / \mathrm{kg}$ of pentagastrin 5-10 min before the study.

D. $0.07 \mathrm{~mL}$ of saturated solution of potassium iodide given to the patient before injection and continued $3 \mathrm{~d}$ after the study.

\section{CASE DISCUSSION}

Meckel diverticulum is the most common congenital abnormality and arises because of persistence of the omphalomesenteric duct (vitelline duct), which normally should obliterate by the fifth week of gestation. It affects approximately $2 \%$ of the population, is usually symptomatic in children less than $2 \mathrm{y}$ old, is located within $61 \mathrm{~cm}$ ( $2 \mathrm{ft}$ ) of the ileocecal valve, and usually has a length of $5 \mathrm{~cm}$ (2 in). Meckel diverticula contain ectopic mucosa in $50 \%$ of the cases, which could include gastric, pancreatic, or colonic tissue (1-3). The diverticulum causes complications in $20 \%$ of the patients, such as gastrointestinal bleeding due to ulceration, acute diverticulitis, intestinal obstruction due to intussusception, or chronic abdominal pain $(4,5)$. The normal gastric mucosa contains not only parietal, chief, and $\mathrm{G}$ cells but also columnar mucin-secreting cells - the cell type that concentrates pertechnetate. Detection of ectopic gastric mucosa is the basis for the Meckel scan (4). Figure 3 illustrates the histology of colonic and gastric mucosa and compares it with the histology of ectopic gastric mucosa from our patient's Meckel diverticulum.

A

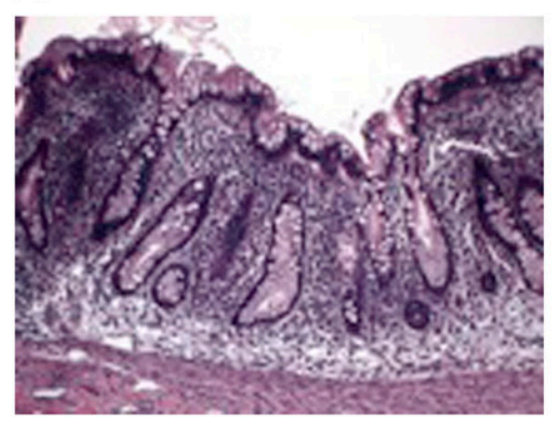

B

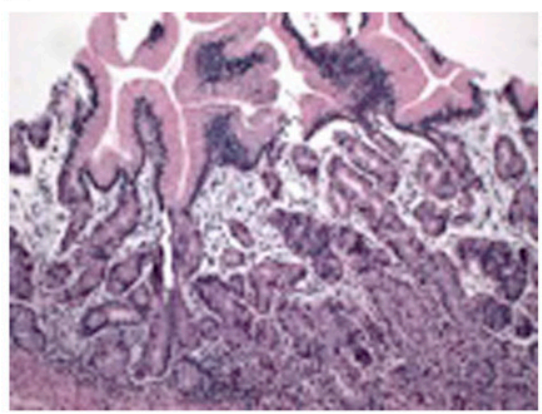

C

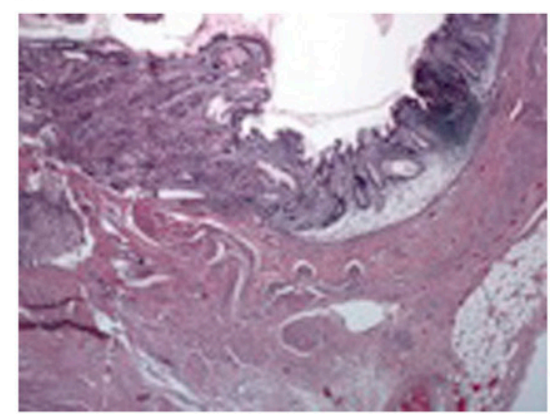

FIGURE 3. (A) Colonic mucosa, (B) gastric mucosa in stomach, and (C) transition point from colonic mucosa to ectopic gastric mucosa in our patient. Left side of slide illustrates ectopic gastric mucosa, with transition to colonic mucosa on right side of slide. 
The pertechnetate scan is more than $85 \%$ sensitive, more than $95 \%$ specific, and $83 \%-88 \%$ accurate in identifying ectopic gastric mucosa. ${ }^{99 \mathrm{~m}} \mathrm{Tc}$-pertechnetate is concentrated by mucoid cells of the gastric mucosa, and its excretion is not dependent on the presence of parietal cells $(3,5)$. The sensitivity of this scan decreases after adolescence because patients who are asymptomatic throughout childhood are less likely to have ectopic gastric mucosa $(1,3)$. A typical positive scan should have a small focus of increased radiotracer accumulation, usually within the right lower quadrant, which appears at the same time as or shortly after visualization of the stomach; however, a small Meckel diverticulum may appear later than the stomach. The intensity of radiotracer activity should increase with time parallel to that of the stomach (6). It is important to realize that a Meckel diverticulum that does not contain gastric mucosa will not be identified by this scan.

\section{ACKNOWLEDGMENT}

The histology photos were prepared by Laura Gonzalez-Krellwitz, from the William Beaumont Hospital Department of Pathology.

\section{REFERENCES}

1. Howarth DM. The role of nuclear medicine in the detection of acute gastrointestinal bleeding. Semin Nucl Med. 2006;36:133-146.

2. Seth A, Seth J. Axial torsion as a rare and unusual complication of a Meckel's diverticulum: a case report and review of the literature. J Med Case Reports. 2011;5:118.

3. Malik AA, Shams-ul-Bari, Wani KA, Khaja AR. Meckel's diverticulum: revisited. Saudi J Gastroenterol. 2010;16:3-7.

4. Kiratli PO, Aksoy T, Bozkurt MF, Orhan D. Detection of ectopic gastric mucosa using ${ }^{99 m}$ Tc-pertechnetate: review of the literature. Ann Nucl Med. 2009;23:97-105.

5. Rossi P, Gourtsoyiannis N, Bezzi M, et al. Meckel's diverticulum: imaging diagnosis. AJR. 1996;166:567-573.

6. Mariani G, Pauwels EK, AlSharif A, et al. Radionuclide evaluation of the lower gastrointestinal tract. J Nucl Med. 2008;49:776-787.

${ }^{*}$ For the answers, see page 20A 